\title{
Development of a High-Performance Flexible Substrate for Flexible Electronics: Joining TAC Films and an Ultra-Thin Glass by Using TEOS-DAC Synthesized by the Sol-Gel Method
}

\author{
Tomoji Ohishi*, Hiroaki Kawada, Tsutomu Yoshida, Takeshi Ohwada \\ Department of Applied Chemistry, Faculty of Engineering, Shibaura Institute of Technology, \\ Tokyo, Japan \\ Email: "tooishi@sic.shibaura-it.ac.jp
}

Received 16 November 2015; accepted 12 December 2015; published 15 December 2015

Copyright $@ 2015$ by authors and Scientific Research Publishing Inc.

This work is licensed under the Creative Commons Attribution International License (CC BY). http://creativecommons.org/licenses/by/4.0/

\section{(c) (i) Open Access}

\begin{abstract}
A new flexible substrate for flexible electronics has been developed. The developed substrate consists of an ultra thin glass and TAC (triacethyl cellulose) film. An ultra thin glass and TAC film were joined with TEOS-DAC (TEOS: tetraethyl orthosilicate, DAC: diacethy cellulose) adhesive resin synthesized by sol-gel method by means of thermo-compression bonding. This substrate has high transparency in visible-light region (90\%), high flexibility (torsion strength and bending strength) and high gas barrier characteristics due to an ultra thin glass. The newly-developed substrate is superior to the substrates fabricated with commercially available adhesive resin in the same way in characteristics of heat resistance, transparency and flexibility.
\end{abstract}

\section{Keywords}

Flexible Electronics, Flexible Substrate, Ultra Thin Glass, Triacethyl Cellulose Film, Organic-Inorganic Adhesive Resin, Sol-Gel Method

\section{Introduction}

In recent years, development of electronics-related products (such as solar cells) and portable information de"Corresponding author.

How to cite this paper: Ohishi, T., Kawada, H., Yoshida, T. and Ohwada, T. (2015) Development of a High-Performance Flexible Substrate for Flexible Electronics: Joining TAC Films and an Ultra-Thin Glass by Using TEOS-DAC Synthesized by the Sol-Gel Method. Materials Sciences and Applications, 6, 1100-1110. http://dx.doi.org/10.4236/msa.2015.612109 
vices (such as mobile phones and hand-held TVs) has continued apace, and development of products with higher performance and higher functionality is being demanded. As next-generation representatives of such products, flexible devices [1]-[4], such as flexible displays [5]-[7] and electronic paper [8] (characterized by thinness, lightness, and bendability) and flexible solar cells, are continuing to be developed. Concurrently, the so-called "flexible electronics" to create those products is drawing a lot of attention [9] [10]. A flexible substrate represents an indispensable component of these flexible products. As for a flexible substrate, an organic polymer film with flexibility is generally used; however, a normal organic film functions poorly as a "gas-barrier" in regard to water vapor, oxygen, etc., and the resulting degradation of performance due to oxidation of the device components fabricated on a flexible substrate has become a big problem. Accordingly, development of a flexible substrate with a good gas-barrier property is being strongly urged. The required performance of a substrate for electronics use is strict; namely, water-vapor permeability must be less than $10^{-2} \mathrm{~g} / \mathrm{m}^{2}$ day in the case of a liquid-crystal device (LCD) and less than $10^{-5}$ to $10^{-6} \mathrm{~g} / \mathrm{m}^{2}$ day in the case of an organic electroluminescence (EL) display [11] [12].

Moreover, as for flexible devices such as displays, they must possess not only a good gas-barrier property but also high transparency and heat resistance. As for a method to improve the gas-barrier property of a normal organic film, an inorganic thin film is formed on top of the organic film. As a simple way of forming an inorganic thin film, this method involves applying a solution containing an inorganic precursor [13]-[17]. However, forming a dense inorganic thin film necessitates heat treatment at high temperature, and the performance of this method has been insufficient because the heat-resistance temperature of the organic film is a problem. Furthermore, elaborate high-vacuum deposition systems (such as atomic layer deposition, sputtering and vacuum-deposition methods) that can form multilayer films at high efficiency are available; however, the high cost of these systems is clearly a problem [18]-[23].

On the other hand, as a substrate material for conventional displays and devices, glass is widely used. Glass has outstanding characteristics in terms of transparency, heat resistance, surface smoothness, and gas-barrier capability, so it is used as a substrate for manufacturing various devices requiring these characteristics. It is known that if the thickness of a glass film is more than a dozen or so microns $(\mu \mathrm{m})$, its permeability of gases will be close to "0" (i.e., completely gas barrier characteristics), and its performance as a gas barrier will be sufficient. However, as an innate weak point concerning glass (namely, an inorganic substance), its brittleness means it is easy to break. Although a glass with thickness of a dozen or so microns becomes more flexible as it becomes thinner, its other weak point—namely, brittleness (or breakability)—becomes worse. The composition of glass and surface modification of glass have been studied, and strengthened ultra-thin glasses have been commercialized [24]. In regard to mechanical strength (i.e., bending strength and torsional strength), however, these glasses are still insufficient. Moreover, they are high-cost products owing to the difficulty of the fabrication techniques involved in making them.

In the present study, an ultrathin glass sheet (with an ordinary brittle configuration) and a triacetyl-cellulose (TAC) film (namely, an optical film commonly used in liquid-crystal devices) were joined by means of an "organic-inorganic hybrid adhesion layer," and a flexible substrate for high-performance (namely, high strength and transparency combined with an outstanding gas-barrier property) flexible electronics was developed.

\section{Experimental}

\subsection{Preparation of TEOS-DAC}

$5.992 \mathrm{~g}$ (28.76 mmol) of tetraethyl orthosilicate (TEOS:TCI Chemicals, >96\%) and $20.00 \mathrm{~g}$ of 1,4-dioxane (TCI Chemicals, $>99 \%$ ) were mixed. Then, under stirring, a solution diluted with $0.136 \mathrm{~g}$ (3.73 mmol) of $12 \mathrm{~N}$ hydrochloric acid (WAKO Co., Special Grade) in $6.00 \mathrm{~g}$ of 1,4-dioxane was added to the mixture. After that, to the mixed solution was added $2.12 \mathrm{~g}$ (11.77 mmol) of deionized water in $5.748 \mathrm{~g}$ of 1,4-dioxane and heated slowly. The solution was stirred at $60^{\circ} \mathrm{C}$ for two hours. And then, $33.00 \mathrm{~g}$ of the TEOS-sol solution was added to a diacetyl cellulose (DAC) solution containing $1.00 \mathrm{~g}(2.5 \mu \mathrm{mol})$ of DAC (DICEL, DAC L-20, polymerization degree: 150) dissolved in $2.00 \mathrm{~g}$ of 1,4-dioxane, and the mixed solution was stirred for two hours at $60^{\circ} \mathrm{C}$. After that, $4.00 \mathrm{~g}$ of cyclohexanone (WAKO Co., Special Grade) was added to the solution, which was then stirred for 10 minutes. As a result of this preparation procedure, $40.00 \mathrm{~g}$ of TEOS-DAC with a compound ratio by weight (i.e., TEOS sol to DAC solution) of 11:1 was produced. Moreover, to study differences due to mixing ratio of the silica $\left(\mathrm{SiO}_{2}\right)$ components and DAC components, TEOS-DAC with various compound ratios by weight of 
DAC solution to TEOS-sol solution was prepared.

\subsection{Fabrication of a Flexible Substrate}

An ultrathin glass sheet (Matsunami Glass Co., borosilicate-glass, $50 \times 40 \mathrm{~mm} /$ thickness: 50 or $70 \mu \mathrm{m}$ ) was coated with TEOS-DAC by means of a dip coater. As for the dipping conditions, lowering speed and immersion time were set to $2.0 \times 10 \mathrm{~mm} / \mathrm{s}$ and 10 seconds, respectively, and the TEOS-DAC was coated on the glass plate at a raising speed of $2.0 \times 10 \mathrm{~mm} / \mathrm{s}$. After that, a TAC film $(60 \times 50 \mathrm{~mm} /$ thickness: $40,60,80$, or $100 \mu \mathrm{m})$ was bonded to the top and bottom sides of the glass plate. Then, multistep heat treatment (i.e., thermo compression bonding ), performed at $80^{\circ} \mathrm{C}$ for 10 minutes, $100^{\circ} \mathrm{C}$ for 40 minutes, $120^{\circ} \mathrm{C}$ for 40 minutes, $140^{\circ} \mathrm{C}$ for 40 minutes, and $160^{\circ} \mathrm{C}$ for 40 minutes, produced a "hybrid flexible substrate." For the purpose of comparison, other flexible substrates that commercial adhesive agents were used were prepared in the same way.

\subsection{Evaluation}

\subsubsection{Flexibility Test}

To evaluate the flexibility of the fabricated substrate, radius-of-curvature-limit tests and torsional-strength tests were performed. As for the radius-of-curvature-limit tests, the fabricated hybrid substrate was formed into a cylindrical shape and fixed with cellophane tape. The cylinder was rolled up, and when the substrate split, the radius of the cylinder was measured. As for the torsional-strength test, both ends of the hybrid substrate were sandwiched between two glass slides and fixed, and both ends of the glass slides were fixed by arms. Then, one of the arms was rotated, and the angle at which the substrate broke was measured.

\subsubsection{Adhesion Test}

Adhesiveness in regard to the substrate of the film and the adhesive agent was evaluated by adhesive tests based on JIS (Japanese Industrial Standard) K 5600-5-6. For these tests, $1001 \times 1$-mm squares were cut into the bonded substrate by a cutter, and a tape was applied with pressure. The applied tape was then torn off in one go (at an angle of 45 degrees), and the number of squares of thin film remaining on the substrate was counted.

\subsubsection{Transmittance Measurement and Cross-Sectional Observation}

Infrared and visible-ultraviolet absorption spectra were respectively measured by Shimadu FT-IR 8400S and Shimadu UV-2450 spectrometers. The cross-sectional structure of the hybrid substrate (in the form of a specimen embedded in resin and ion polished for observation) was observed by scanning electron microscope (SEM; a Carl Zeiss ULTRA55).

\section{Result and Discussion}

\subsection{Design Concept of Flexible Substrate}

As for the organic-inorganic hybrid substrate developed in this study, the flexible substrate is configured as a "sandwich" as follows. At the core of the sandwich is an ultrathin glass sheet with a certain amount of flexibility (even though it is thin and brittle) plus an excellent gas-barrier property and high transparency. The glass sheet is sandwiched between organic films (with high flexibility and transparency), as the top and bottom surfaces of the substrate, by using an organic-inorganic hybrid adhesive resin as an adhesive layer between the glass sheet and the organic films. A cross-section of the sandwich structure is shown in Figure 1. Thanks to the glass core of the substrate, a perfect gas barrier is maintained, and the organic films compensate for the brittleness of the glass substrate. Moreover, the substrate exploits the high transparency of both the organic films and the ultrathin glass core. As for the key feature of the developed substrate, its flexibility and strength can be significantly improved by a simple method (namely, an intrinsically brittle and breakable glass sheet is laminated by organic films on its upper and lower surfaces). This is because the adhesive resin buries the "chipping" of the end facets and surfaces of the glass layer (caused by the glass-fabrication process) by means of the adhesive layers, and the organic films (which form the exterior faces of the substrate) disperse the stress applied to the glass.

A TAC film (with comparatively high heat resistance in organic films and outstanding characteristic as an optical film) was selected as the organic material, and an ultrathin borosilicate-glass sheet (thickness: 70 or $50 \mu \mathrm{m}$ ) was selected as the inorganic material. To laminate these two materials, it is necessary to design an adhesive layer 


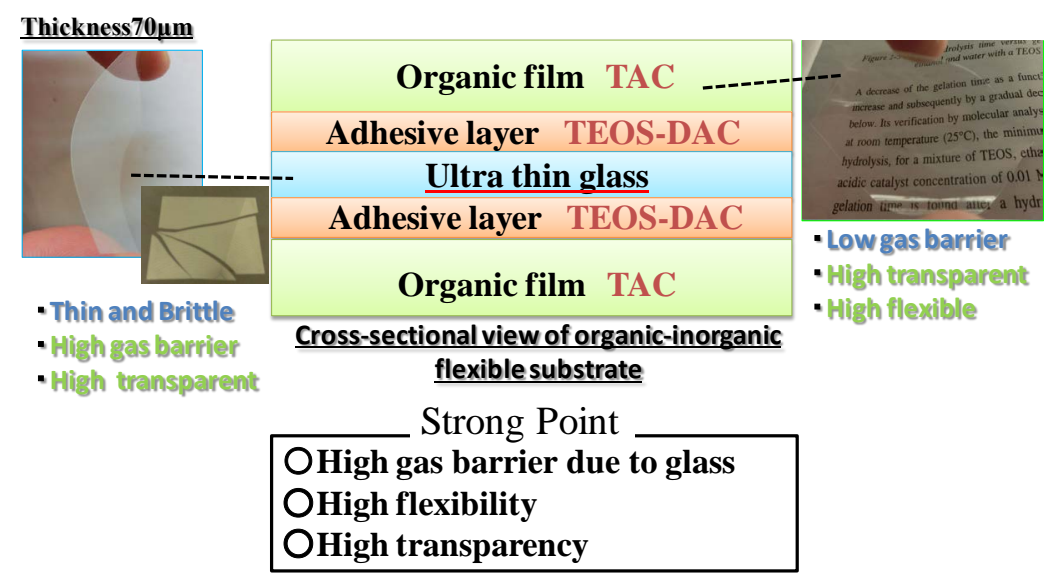

Figure 1. Cross-sectional view of organic-inorganic flexible substrate and strong point.

with adhesiveness in regard to both organic and inorganic materials. Accordingly, in the present study, an adhesive resin for bonding together an organic-inorganic hybrid multilayer substrate was designed. The concept behind the $\mathrm{SiO}_{2}$-diacetylcellulose (DAC) hybrid resin (tetraethyl orthosilicate (TEOS)-DAC) developed in this study is shown in Figure 2. DAC, obtained by acetylization of two hydroxyl groups of cellulose (composed of cellulose molecules with similar structures to that of TAC), was used for the organic polymer unit. In addition, a $\mathrm{SiO}_{2}$ sol (that is, TEOS hydrolyzed and polycondensed by the sol-gel method) was used for the inorganic polymer unit. The DAC and $\mathrm{SiO}_{2}$ sol are chemically bonded by dehydration polycondensation of a silanol group in the $\mathrm{SiO}_{2}$ sol and a hydroxyl group (-OH) in the DAC by the sol-gel method.

The TEOS-DAC adhesive exerts a strong adhesive force in regard to the TAC film due to interdiffusion (since DAC has a similar structure to the TAC film) and hydrogen bonding between the hydroxyl group (-OH) in the acetylcellulose and a carbonyl $(-\mathrm{C}=\mathrm{O})$ in an acetyl group $\left(\mathrm{CH}_{3} \mathrm{CO}\right)$. Moreover, it bonds with the ultrathin glass substrate by chemical bonding, namely, siloxane bonding (-Si-O-Si-), between a silanol group (-Si-OH) in the $\mathrm{SiO}_{2}$ sol and a similar one in the outermost surface of the substrate. Since it has adhesiveness in regard to organic and inorganic materials in this manner, the TEOS-DAC hybrid resin can bond materials that are difficult to bond by nature.

Although the TAC film functions poorly as a gas barrier, (thickness: $60 \mu \mathrm{m}$; water-vapor transmission rate: $472 \mathrm{~g} / \mathrm{m}^{2}$ day at $40^{\circ} \mathrm{C} / 90 \% \mathrm{RH}$ ), the gas-barrier property is significantly improved by the method (i.e. utilizing the TEOS-DAC hybrid resin) described above. This method is drawing attention from not only the viewpoint of the high mechanical strength of glass but also the viewpoint of the high performance of the organic film.

\subsection{Synthetic Procedure of Organic-Inorganic Hybrid Resin (TEOS-DAC) for Adhesive Bonding}

The procedure for synthesis of TEOS-DAC is shown in Figure 3. As a starting constituent for TEOS, a sol-gel reaction is initiated in dioxane solvent. DAC is added to that solution, the reaction is propagated further, and the TEOS-DAC organic-inorganic hybrid adhesive is synthesized. As for this reaction, concentration of the $\mathrm{SiO}_{2} \mathrm{sol}_{\text {, }}$ molecular weight of the DAC, and composition ratio of TEOS to DAC were varied, and their effects on the strength of the hybrid substrate were evaluated.

Infrared spectra of the TEOS-DAC organic-inorganic hybrid resin with that of starting material are shown in Figure 4. In regard to the starting-material inorganic polymer (TEOS-sol), stretching-vibration peak (Si-O-Si) can be seen near $1102 \mathrm{~cm}^{-1}$. In addition, in regard to the organic polymer (DAC), stretching-vibration peak $(\mathrm{C}=\mathrm{O})$ derived from an acetyl group can be seen near $1733 \mathrm{~cm}^{-1}$. Furthermore, in regard to TEOS-DAC, the stretching-vibration peak (Si-O-Si) near $1102 \mathrm{~cm}^{-1}$ and the stretching-vibration peak $(\mathrm{C}=\mathrm{O})$ near $1733 \mathrm{~cm}^{-1} \mathrm{de}-$ rived from an acetyl group can both be seen. These spectra confirm that a hybrid material composed of an inorganic material (TEOS-sol) and an organic material (DAC) was successfully formed. TEOS-DAC is expected to form chemical bonding by dehydrative polycondensation of an $\mathrm{OH}$ group in DAC and a $\mathrm{Si}-\mathrm{O}-\mathrm{H}$ group in the TEOS-sol or mutual interaction between hydrogen bonds (involving strong interaction between molecules). 




Figure 2. Schematic drawing of TEOS-DAC adhesive.



Figure 3. Synthetic procedure of TEOS-DAC.

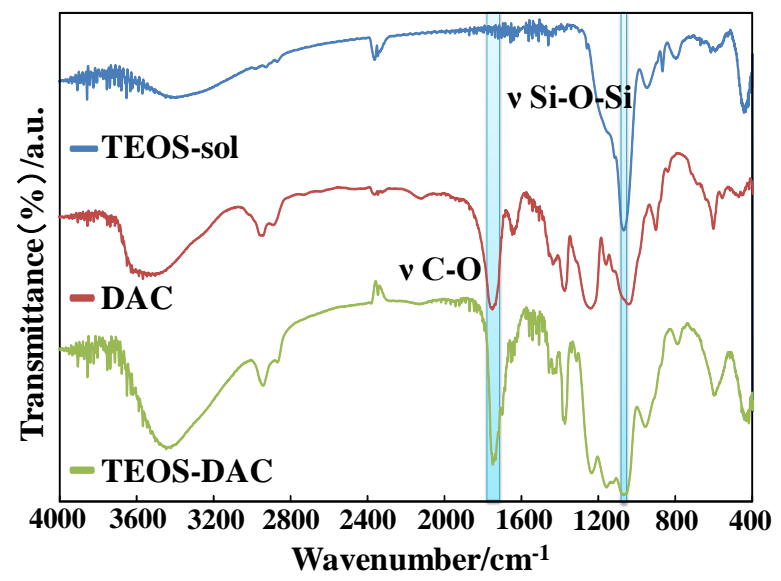

Figure 4. Infrared spectra of TEOS-DAC, TEOS sol and DAC.

\subsection{Fabrication and Properties of a Hybrid Flexible Substrate}

The fabrication process for a flexible substrate formed by using a TEOS-DAC adhesive layer is shown in Figure 5. First, a film of adhesive hybrid resin is dip coated onto an ultrathin glass substrate. After that, the film is sandwiched between TAC films by processing with a laminator. Next, the ultrathin glass and TAC films are thermo compressively bonded by multi-stage heat treatment. 70- or 50- $\mu$ m-thick glass is used for the glass substrate, and 100, 80, 60, or 40- $\mu$ m-thick TAC film was used for the organic film. The water (b.p.: $100^{\circ} \mathrm{C}$ ), $1,4-$ 


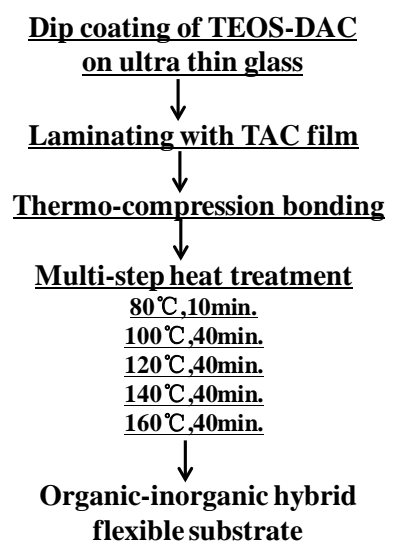

Figure 5. Fabrication process of organic-inorganic hybrid flexible substrate.

dioxane (b.p.: $101.1^{\circ} \mathrm{C}$ ) and cyclohexanone (b.p.: $155.7^{\circ} \mathrm{C}$ ) solvents contained in the TEOS-DAC can be gradually removed by evaporation by multi-step heat treatment, and uniformity of the interfaces of the fabricated substrate is assured. If the substrate is suddenly heated to a temperature of $160^{\circ} \mathrm{C}$, bubbles are generated at the substrate interfaces, and the glass and TAC film detach. The temperature at multi-step heat treatment was chosen according to boiling point of the used solvents in TEOS-DAC and the results of TG-DTA of TEOS-DAC resin. The hybrid substrate was pre-dried at $80^{\circ} \mathrm{C}$ for $10 \mathrm{~min}$. and then raised to $100^{\circ} \mathrm{C}$ (for $40 \mathrm{~min}$.) to eliminate $\mathrm{H}_{2} \mathrm{O}$. The 1,4-dioxane and cyclohexanone were removed at $120^{\circ} \mathrm{C}$ for $40 \mathrm{~min}$. and at $140^{\circ} \mathrm{C}-160^{\circ} \mathrm{C}$ for $40 \mathrm{~min}$., at temperature higher than boiling point temperature, respectively. During evaporation of the vaporized solvents, TEOS-DAC might be diffused into TAC film, leading to uniformity of the interfaces between TEOS-DAC and TAC.

Transmittance spectra and exterior photos of the fabricated flexible hybrid substrate are shown in Figure 6. It is clear from this result that the transparency of substrate is high; in particular, the transmissivity for visible light in the wavelength range of 400 to $800 \mathrm{~nm}$ is about $90 \%$. Although the absorption around $400 \mathrm{~nm}$ increases by $1 \%$ to $2 \%$ compared to the transmissivity of the glass film and TAC film, its transparency in the visible-light region is very high. Moreover, thanks to the high flexibility of the substrate, the glass does not break and the TAC film does not peel off.

Adhesive strength of the TEOS-DAC adhesive in regard to the glass and TAC films is extremely high, namely, 100/100 (residual number/cut number), according to the results of a tape test (performed in accordance with the appropriate JIS standard). Moreover, the adhesive strength of the bonded flexible substrate was evaluated by tape test. The test results (shown in Figure 7) reveal that it depends on the compositional ratio of $\mathrm{SiO}_{2}$ in the DAC of the TEOS-DAC. In the case of DAC only (i.e., zero $\mathrm{SiO}_{2}$ concentration), the adhesive strength is just about zero. This is because the DAC is bonded to the glass film by Van der Waals bonding only, and chemical bonding with the glass substrate does not occur. When the concentration of $\mathrm{SiO}_{2}$ exceeds $20 \%$, adhesive strength rises rapidly, reaching a maximum around $35.5 \%$ to $60 \%$. It is supposed that this is because siloxane bonds form between the glass substrate and the TEOS-DAC adhesive layers. When the concentration of $\mathrm{SiO}_{2}$ increases from $60 \%$ to $80 \%$, the adhesive strength gradually decreases. The cause of this decrease is considered to be the effect of $\mathrm{SiO}_{2}$ particles precipitating in the adhesive. When the silica component increases, precipitation of $\mathrm{SiO}_{2} \mathrm{par}^{-}$ ticles can be seen in the adhesive layers. Furthermore, when it surpasses $80 \%$, the adhesive force in regard to the TAC film weakens, and bonding between the glass substrate and the TAC films becomes impossible. It can thus be concluded that to strongly bond the glass substrate and the TAC films the compositional ratio of the organic to inorganic components has an optimal range.

\subsection{SEM Observation}

Cross-sectional SEM photographs of the fabricated flexible substrate are shown in Figure 8. Here, a 50- $\mu \mathrm{m}$ ultrathin glass and a $40-\mu \mathrm{m}$ TAC film are bonded by a TEOS-DAC adhesive layer. In particular, it is clear that the TAC film is uniformly bonded to the glass in a satisfactory interfacial state. Moreover, a clear-cut layer at the 




Figure 6. Absorption spectra of flexible substrate and exterior photos.

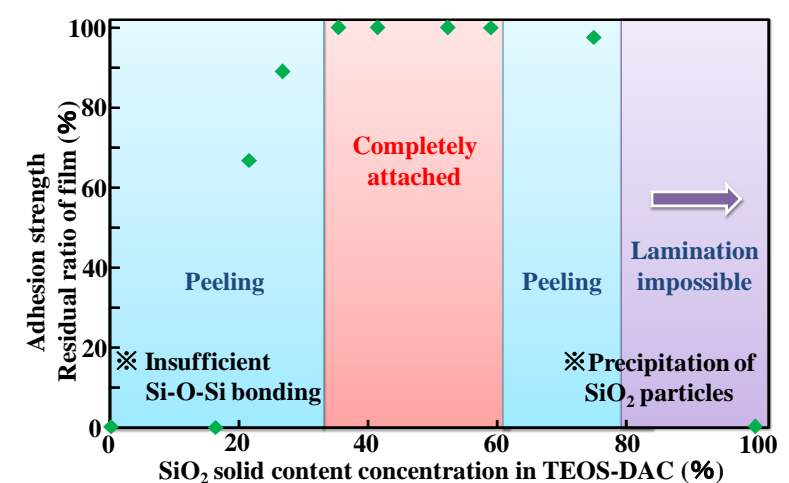

Figure 7. Affect on adhesive composition to adhesiveness.



Figure 8. Cross-sectional photographs of hybrid flexible substrate.

interface of the adhesive and TAC film cannot be seen as shown in enlarged image (a'). It is supposed that this is because the DAC component of the adhesive agent and the structural constituents of the TAC film are similar, so they are unified during the thermo-compression bonding used to fabricate the substrate. As a result, high adhesive strength between the adhesive agent and the TAC component is created. Moreover, in regard to the glass substrate, the silica component of the TEOS-DAC forms chemical bonds ( $\mathrm{Si}-\mathrm{OH})$ with the glass surface, thereby increasing the adhesive strength of the joint. As shown in image (b), which is a cross section of a sample fabricated by forming only an adhesive layer of TEOS-DAC on an ultrathin glass substrate, a uniform layer (with 
thickness of $14.6 \mu \mathrm{m}$ ) was formed. On the other hand, as for the flexible substrate formed by laminating a TAC film ( $40 \mu \mathrm{m}$ thick) on this TEOS-DAC layer [center of image (a)], the actual TAC/TEOS-DAC film thickness is $40 \mu \mathrm{m}$, which is much lower than the simply totaled thicknesses of the TAC film and TEOS-DAC adhesive layer (i.e., $54.6 \mu \mathrm{m}$ ). This result suggests that the TEOS-DAC and TAC layers are combined during the thermo-compression treatment.

\subsection{Mechanical Strength of Hybrid Flexible Substrates}

To evaluate the flexibility of the fabricated substrate, torsional-strength and radius-of-curvature-limit test were performed. The appearance of the tests is shown in Figure 9. In the torsional-strength test, both ends of the substrate are fixed, one end of the substrate is twisted, and the angle at which cracks are generated ("fracture angle" hereafter) is measured. It is judged that the bigger the angle, the greater the flexibility of the substrate. The ultrathin glass layer is particularly weak in regard to the applied twisting. In the radius-of-curvature-limit test, the substrate is rolled up into a tube, and the radius of the tube at which cracks appear $(r)$ is recorded. It is judged that the smaller the value of $r$, the higher the flexibility of the substrate. Figure 9 shows the results of torsional-strength test and radius-curvature-limit test for the hybrid substrate using TEOS-DAC $\left(\mathrm{SiO}_{2}\right.$ content 59.9\%), $50 \mu \mathrm{m}$ ultra thin glass and $100 \mu \mathrm{m}$ TAC film. This hybrid substrate shows no cracks at $50^{\circ}$ torsion angle for torsional-strength test and $r=5 \mathrm{~mm}$ for radius-of-curvature limit test, indicating high flexibility.

The results of the torsional-strength and radius-of-curvature limit tests on the fabricated flexible hybrid substrate, in which the $\mathrm{SiO}_{2}$ solid-content ratio in TEOS-DAC was 59\% (which gives high adhesiveness between the glass substrate and TAC film), are shown in Figure 10. The thicknesses of the ultrathin glass substrate and TAC film were varied, namely, 70 or $50 \mu \mathrm{m}$ and $40,60,80$, or $100 \mu \mathrm{m}$, respectively. According to the torsional-strength test, although the fracture angle of bulk glass ranges from $12.8^{\circ}\left(70 \mu \mathrm{m}\right.$ thick) to $18.2^{\circ}(50 \mu \mathrm{m})$, the angle is significantly increased when the bulk glass is bonded with TAC films. That angle increases as the thickness of the TAC film increases; in other words, when the thickness of the ultrathin glass substrate is $70 \mu \mathrm{m}$, if TAC-film thickness is increased (i.e., from 40 , to 60,80 , and $100 \mu \mathrm{m}$ ), the flexibility of the film is respectively improved from $39.2^{\circ}$, to $47.8^{\circ}, 47.8^{\circ}$, and $54.5^{\circ}$. As for the $50-\mu \mathrm{m}$-thick ultrathin glass substrate, the flexibility was improved even more, namely, from $52.0^{\circ}$ at $40-\mu \mathrm{m}$ thickness, to $56.0^{\circ}$ at $60 \mu \mathrm{m}, 63.8^{\circ}$ at $80 \mu \mathrm{m}$, and $71.8^{\circ}$ at $100 \mu \mathrm{m}$. On the other hand, in the radius-of-curvature limit tests, the $r$ values for the glass bulk were $19.1 \mathrm{~mm}$ (70 $\mu \mathrm{m}$ thick) and $15.1 \mathrm{~mm}$ (50 $\mu \mathrm{m}$ thick). The value of $r$ is decreased by bonding the glass with the TAC film. When the ultrathin glass substrate is $70 \mu \mathrm{m}$ thick, its flexibility is improved, namely, from $11.8 \mathrm{~mm}(40-\mu \mathrm{m}-$ thick TAC film), to $10.5 \mathrm{~mm}(60 \mu \mathrm{m}), 9.7 \mathrm{~mm}(80 \mu \mathrm{m})$, and $8.2 \mathrm{~mm}(100 \mu \mathrm{m})$. When the ultrathin glass substrate is $50 \mu \mathrm{m}$ thick, its flexibility is further improved, namely, from $7.6 \mathrm{~mm}$ ( $40-\mu \mathrm{m}$-thick TAC film), to 7.3 $\mathrm{mm}(60 \mu \mathrm{m}), 4.6 \mathrm{~mm}(80 \mu \mathrm{m})$, and $4.0 \mathrm{~mm}(100 \mu \mathrm{m})$.

In conclusion, by fabricating a hybrid substrate, flexibility was significantly improved in comparison to the



Figure 9. Appearance of evaluation for flexibility of the developed substrate. 




Figure 10. Affect on materials thickness to flexibility.

Table 1. Comparison of characteristics of the developed substrate using TEOS-DAC and the substrates using commercially available adhesives.

\begin{tabular}{|c|c|c|c|c|c|c|}
\hline Adhesive & Epoxy & Urethane & Silicon & Cyano acrylate & Butyl rubber & TEOS-DAC \\
\hline Transparency & Transparent & Bubble generation & Opaque & Transparent & Bubble generation & Transparent \\
\hline Adhesiveness & $100 / 100$ & $100 / 100$ & $100 / 100$ & $87 / 100$ & 0 & $100 / 100$ \\
\hline $\begin{array}{c}\text { Transparency } \\
\text { (after } 180^{\circ} \mathrm{C} \text { treatment) }\end{array}$ & Yellowish & $\begin{array}{c}\text { Yellowish } \\
\text { bubble generation }\end{array}$ & Opaque & Transparent & $\begin{array}{c}\text { Deformation } \\
\text { bubble generation }\end{array}$ & Transparent \\
\hline $\begin{array}{c}\text { Adhesiveness } \\
\text { (after } 180^{\circ} \mathrm{C} \text { treatment) }\end{array}$ & $100 / 100$ & $100 / 100$ & $100 / 100$ & 0 & $80 / 100$ & $100 / 100$ \\
\hline Torsion strength $\left(^{\circ}\right)$ & 28.0 & 23.8 & 31.3 & 31.0 & 25.0 & 47.8 \\
\hline Curvature limit radius (mm) & 18.3 & 19.9 & 14.8 & 15.6 & 17.5 & 10.5 \\
\hline
\end{tabular}

Tape test for adhesiveness: Residual number/Cut number. TAC film $60 \mu \mathrm{m}$, Ultra thin glass $70 \mu \mathrm{m}$.

bulk ultrathin glass substrate. Moreover, it was revealed that the value of flexibility depends on the thickness of the glass and the thickness of the TAC film. The flexibility is accomplished by burying the chipping of the end facets and glass surface by the adhesive layer and dispersing the stress applied to the glass by TAC film.

\subsection{Comparison with Commercial Adhesives}

The performance characteristics of the flexible substrate fabricated using TEOS-DAC in this study and of substrates fabricated in a similar way (but using commercially available adhesives) are compared in Table 1. The substrates were fabricated by using $70-\mu \mathrm{m}$-thick glass and $60-\mu \mathrm{m}$ TAC films, and the types of adhesives used were commercial epoxy, urethane, cyanoacrylate, and butyl-rubber. The characteristics compared are transparency, adhesiveness, heat resistance (transparency and adhesiveness after heat treatment at $180^{\circ} \mathrm{C}$ ), torsional strength, and radius-of-curvature limit. As for the commercial adhesives, transparency, adhesiveness, and/or heat resistance are insufficient in all or some cases. Moreover, in all cases, torsional strength and radius-of-curvature limit are also lagging compared to those of the substrate developed in this study by utilizing TEOS-DAC. In regard to all the performance characteristics, the developed TEOS-DAC hybrid substrate exhibits superior performance in comparison to all the substrates fabricated with commercial adhesives. Furthermore, after heat treatment at $200^{\circ} \mathrm{C}$, that superior performance does not appear to change, demonstrating that the heat resistance of the developed substrate is high.

\section{Conclusion}

Under the aim of developing a flexible substrate with outstanding performance in terms of gas-barrier capability, flexibility, and transparency, a new flexible substrate was fabricated by bonding an ultrathin glass and TAC films by means of a TEOS-DAC adhesive. The method for fabricating the substrate, namely, bonding by thermo-compression, is quick and easy. The flexibility of the developed substrate (in terms of torsional strength and radius-of-curvature limit) is outstanding, and its transparency in the visible-light region is high (i.e., 90\%). 
Moreover, after heat treatment at $180^{\circ} \mathrm{C}-200^{\circ} \mathrm{C}$, its outstanding performance does not change, demonstrating that the heat resistance of the substrate is also high. Owing to these outstanding characteristics, it is expected that the developed substrate will be applied as a substrate for flexible electronics.

\section{Acknowledgements}

This work was partially supported by JSPS KAKENHI Grant Number 26420711.

\section{References}

[1] White, M.S., Kaitenbrunner, M.G., Istrokowacki, E.D., Gutnichenko, K., Kettlgruber, G., Graz, I., Aazou, S., Ulbricht, C., Egbe, D.A.M., Miron, M.C., Major, Z., Schaber, M.C., Sekitani, T., Someya, T., Bauer, S. and Sariciftci, N.S. (2013) Ultrathin Highly Flexible and Stretchable PLEDs. Nature Photonics, 7, 811-816. http://dx.doi.org/10.1038/nphoton.2013.188

[2] Sekitani, T. and Someya, T. (2011) Human-Friendly Organic Integrated Circuit. Materials Today, 14, 398-407. http://dx.doi.org/10.1016/S1369-7021(11)70184-5

[3] Sekitani, T., Zschieschang, U., Klauk, H. and Someya, T. (2010) Flexible Organic Transistor and Circuits with Extreme Bending Stability. Nature Materials, 9, 1015-1022. http://dx.doi.org/10.1038/nmat2896

[4] Nomura, K., Ohta, H., Kamiya, T., Hirano, M. and Hosono, H. (2004) Room-Temperature Fabrication of Transparent Flexible Thin-Film Transistors Using Amorphous Oxide Semiconductors. Nature, 432, 488-492. http://dx.doi.org/10.1038/nature03090

[5] Katsuhara, M., Yagi, I., Yumoto, A., Noda, M., Hirai, N., Yasuda, R., Moriwaki, T., Ushikura, S., Imaoka, A., Urabe, T. and Nomoto, K. (2010) A Flexible OLED Display with an OTFT Backplane Made by Scalable Manufacturing Process. Journal of the Society for Information Display, 18, 399-404. http://dx.doi.org/10.1889/JSID18.6.399

[6] Yagi, I., Hirai, N., Miyamoto, Y., Noda, M., Imaoka, A., Yoneda, N., Nomoto, K., Kasahara, J., Yumoto, A. and Urabe, T. (2008) A Flexible Full-Color AMOLED Display Driven by OTFTs. Journal of the Society for Information Display, 16, 15. http://dx.doi.org/10.1889/1.2835023

[7] Uesaka, S., Yamaoka, R., Sasaki, T., Chida, A., Kawashima, S., Isa, T., Seo, S., et al. (2014) A 13.5-in. Quad-FHD Flexible CAAC-OS AMOLED Display with Long-Life OLED Device Structure. Journal of the Society for Information Display, 22, 603-612. http://dx.doi.org/10.1002/jsid.275

[8] Kodaira, T., Hirabayashi, S., Komatsu, Y., Miyasaka, M., Kawai, H., Nebashi, S., Inoue, S. and Shimoda, T. (2008) A Flexible 3.1-in. Active-Matrix Electrophoretic Display with High Resolution and A Thickness of $100 \mu$ m. Journal of the Society for Information Display, 16, 107-111. http://dx.doi.org/10.1889/1.2835015

[9] Wong, W.S. and Salleo, A. (2009) Flexible Electronics: Materials and Applications. Springer, New York. http://dx.doi.org/10.1007/978-0-387-74363-9

[10] Sekitani, T. and Someya, T. (2010) Stretchable Large-Area Organic Electronics. Advanced Materials, 22, $2228-2246$. http://dx.doi.org/10.1002/adma.200904054

[11] MacDonald, M.A., Looney, M.K., MacKerron, R., Adam, R., Hashimoto, K. and Rakos, K. (2007) Latest Advances in Substrates for Flexible Electronics. Journal of the Society for Information Display, 15, 1075-1083. http://dx.doi.org/10.1889/1.2825093

[12] Nakayama, H. and Ogawa, S., Eds. (2011) Advanced Thin-Film Processes for Gas-Barrier Films-Toward the Industrialization of High-Grade Gas-Barrier Films for Electronics. CMC, Tokyo.

[13] Brinker, C.J. and Schere, G.W. (1990) Sol-Gel Science. Academic Press, Boston.

[14] Seyferth, D. and Wiseman, G.H. (1984) High-Yield Synthesis of $\mathrm{Si}_{3} \mathrm{~N}_{4} / \mathrm{SiC}$ Ceramic Materials by Pyrolysis of a Novel Polyorganosilazane. Journal of American Ceramic Society, 37, C132-C133.

[15] Kamiya, K., Oka, A.I., Nasu, H. and Hashimoto, T. (2000) Comparative Study of Structure of Silica Gels from Different Sources. Journal of Sol-Gel Science \& Technology, 19, 495-499. http://dx.doi.org/10.1023/A:1008720118475

[16] Iwamoto, Y., Sato, K., Kato, T., Inada, T. and Kubo, Y. (2005) A Hydrogen-Perselective Amorphous Silica Membrane Derived from Polysilazane. Journal of European Ceramic Society, 25, 257-264. http://dx.doi.org/10.1016/j.jeurceramsoc.2004.08.007

[17] Funayama, O., Tshiro, Y., Kamo, A., Okumura, M. and Isoda, T. (1994) Conversion Mechanism of Perhydropolysilazane into Silicon Nitride-Base Ceramics. Journal of Material Science, 29, 4883-4888. http://dx.doi.org/10.1007/BF00356538

[18] Carcia, P.F., Mclean, R.S., Groner, M.D., Dameron, A.A. and George, S.M. (2009) Gas Diffusion Ultrabarriers on Polymer Substrates Using $\mathrm{Al}_{2} \mathrm{O}_{3}$ Atomic Layer Deposition and SiN Plasma-Enhanced Chemical Vapor Deposition. Jour- 
nal of Applied Physics, 106, Article ID: 023533. http://dx.doi.org/10.1063/1.3159639

[19] Yagi, Y. and Akashi, K. (2007) Passivation Films on Organic Film Substrates Designed for Organic Electroluminescence Device. Journal of Vacuum Society of Japan, 50, 735-738. http://dx.doi.org/10.3131/jvsj.50.735

[20] Hanada, T., Negishi, T., Shiroishi, I. and Shiro, T. (2010) Plastic Substrate with Gas Barrier Layer and Transparent Conductive Oxide Thin Film for Flexible Displays. Thin Solid Films, 518, 3089-3092. http://dx.doi.org/10.1016/j.tsf.2009.09.166

[21] Hata, T. and Nakayama, H. (2008) An Organic Catalytic CVD: Principle, Apparatus and Applications. Thin Solid Films, 516, 558-563. http://dx.doi.org/10.1016/j.tsf.2007.06.093

[22] Carcia, P.F., MacLean, R.S., Reilly, M.H., Groner, M.D. and George, S.M. (2006) Catalyst of $\mathrm{Al}_{2} \mathrm{O}_{3}$ Gas Diffusion Barriers Grown by Atomic Layer Deposition on Polymer. Applied Physics Letters, 89, Article ID: 031915. http://dx.doi.org/10.1063/1.2221912

[23] Dameron, A.A., Davidson, S.D., Burton, B.B., Carcia, P.F., MacLean, R.S. and George, S.M. (2008) Gas Diffusion Barriers on Polymer Using Multi Layers Fabricated by $\mathrm{Al}_{2} \mathrm{O}_{3}$ and Rapid $\mathrm{SiO}_{2}$ Atomic Layer Deposition. Journal of Physical Chemistry C, 112, 4573-4580. http://dx.doi.org/10.1021/jp076866+

[24] http://www.neg.co.jp/JP/technology/pdf/93-p090.pdf 